\title{
Characterization, source, and retention of microplastic in sandy beaches and mangrove wetlands of the Qinzhou Bay, China
}

\author{
Jia Li ${ }^{\mathrm{a}, \mathrm{b}}$, Hua Zhang ${ }^{\mathrm{b}, *}$, Kaina Zhang ${ }^{\mathrm{c}}$, Ruijuan Yang ${ }^{\mathrm{b}}$, Ruize $\mathrm{Li}^{\mathrm{b}}$, Yanfang $\mathrm{Li}^{\mathrm{b}}$ \\ ${ }^{a}$ School of Environmental Science and Engineering, Yangzhou University, Yangzhou 225127,China \\ ${ }^{\mathrm{b}}$ Key Laboratory of Coastal Environmental Process and Ecology Remediation, Yantai Institute of Coastal Zone Research, Chinese Academy of Sciences, Yantai 264003, \\ China \\ ${ }^{\mathrm{c}}$ School of Environment and Materials Engineering, YanTai University, Yantai 264003, China
}

A R T I C L E I N F O

\section{Keywords:}

Microplastics

Mangrove

Beach

Aquaculture

Retention

\begin{abstract}
A B S T R A C T
Severe microplastic pollution from anthropogenic activities in coastal zones presents an imminent risk to marine ecosystems. In this study, abundant microplastics (15-12,852 items $\mathrm{kg}^{-1}$ ) with sizes ranging between 0.16 and $5.0 \mathrm{~mm}$ were extracted from 17 sediment samples collected in sandy beaches and mangrove wetlands of the Qinzhou Bay, Guangxi Province, Southwest China. Three types of microplastics (i.e. polystyrene, polypropylene, and polyethylene) were identified with Fourier transform infrared (FTIR) spectroscopy analysis. These detected microplastics were characterized by different colors (white, transparent, yellow, green, red, and blue) and shapes (fragment, fiber, and sphere). Microplastics were concentrated on supratidal beaches and wetlands outside of mangrove, and less abundant on intertidal beaches and inside of mangrove wetlands. Meanwhile, high microplastic concentrations were observed near mollusk farms. The spatial distribution and chemical speciation indicated that microplastics were derived from disintegration of large plastic debris (e.g., Styrofoam buoys used to support mollusk rafts) abandoned by aquaculture industry. Further, coastal vegetation (e.g. mangrove) could trap microplastic particles.
\end{abstract}

\section{Introduction}

Microplastics have been ubiquitously detected in water, sediments, and beaches, at high concentrations (Moret-Ferguson et al., 2010; Woodall et al., 2014; Fok et al., 2017). Due to their size similarity to algae and sediment, microplastics can be ingested by plankton, bivalves, lobster, fish, and accumulate in food webs (Lee et al., 2013; Wright et al., 2013; Bakir et al., 2014; Ivar do Sul and Costa, 2014; Van Cauwenberghe and Janssen, 2014). The toxic additives contained in plastics can be released to the environment, then causing potential harm to organisms (Koelmans et al., 2014). Meanwhile, microplastics are also considered as carriers of various toxins and hydrophobic organic pollutants (Guo et al., 2012; Batel et al., 2016; Hueffer and Hofmann, 2016; Li et al., 2018).

Land-based sources and maritime activities can carry large loads of plastic debris to coastal environments (Li et al., 2016; Auta et al., 2017). Numerous studies have determined that microplastics concentrations on sandy beaches and subtidal sediments are extremely high (Lee et al., 2013; Dekiff et al., 2014; Mathalon and Hill, 2014; Yu et al., 2016). Furthermore, recent studies have identified high abundance of microplastics in mangrove and salt marsh habitats and suggested that the vegetation of wetlands is an effective retaining media of microplastics (Nor and Obbard, 2014; Sutton et al., 2016; Weinstein et al., 2016). Therefore, coastal wetlands might be an important reservoir of microplastics. Qinzhou Bay is located on the coast of Guangxi Province, southwest China and is the largest natural breeding areas of Magallana rivularis (Gould, 1861). There are $>23,000$ acres of mollusk farming located in this area. Styrofoam floats are intensively used in hangingculture farms for mollusk. Intensive aquaculture activities may make the Qinzhou Bay a hotspot for microplastics pollution. The intertidal zones of the inner bay and adjacent coastlines are dominated by mangrove forests, which may influence the retention of microplastics. Furthermore, high temperature and strong solar ultraviolet light associated with tropical climate can accelerate the degradation of plastic debris in coastal zones (Heo et al., 2013). However, there is currently no data can reveal the source and retention of microplasitc pollution in coastal zones of the Qinzhou Bay.

This study aimed to investigate microplastic pollution in the Qinzhou bay. 17 sediment samples were collected to determine the occurrence and spatial distribution of microplastics. Microplastics were

\footnotetext{
* Corresponding author.

E-mail address: hzhang@yic.ac.cn (H. Zhang).
} 

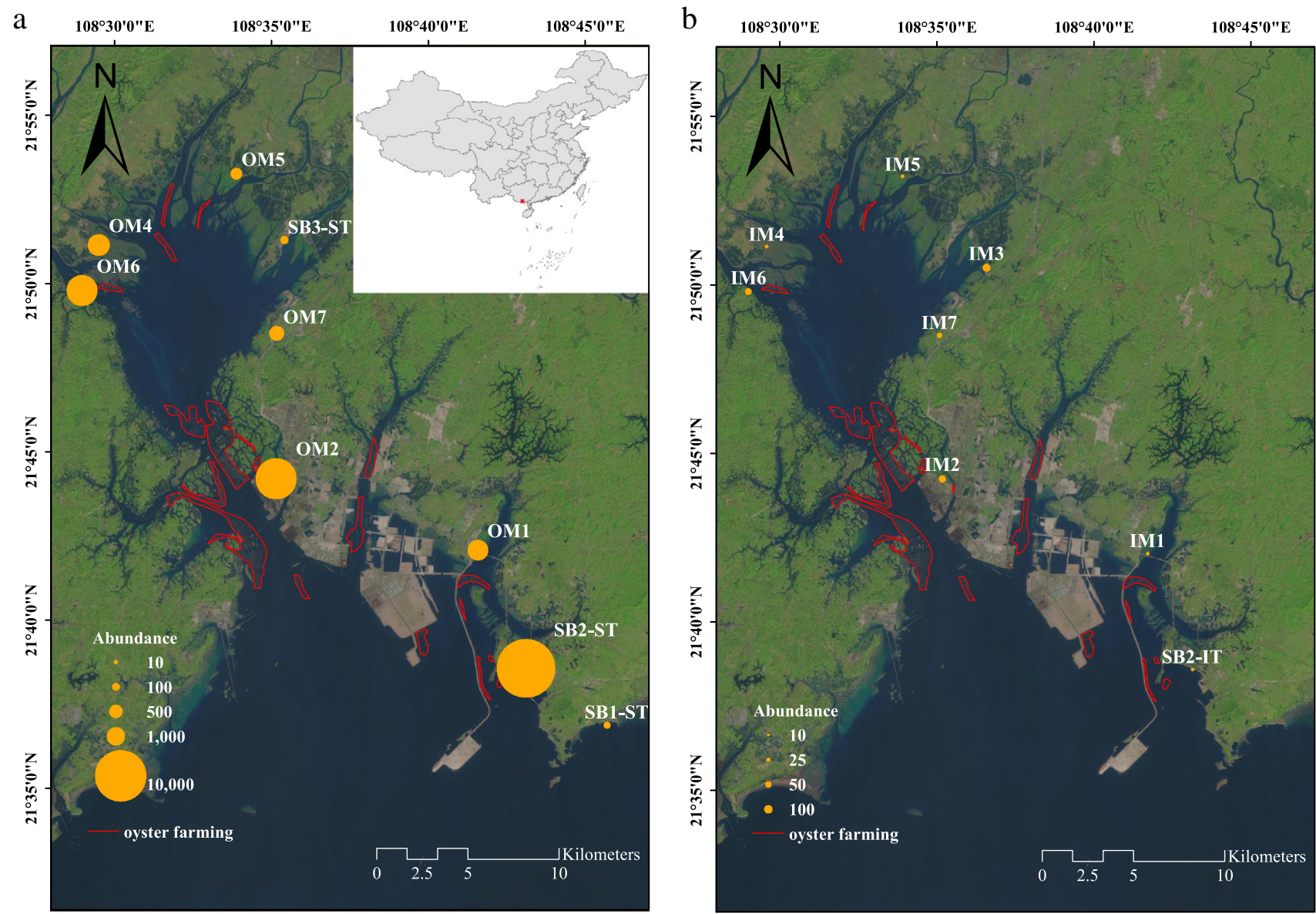

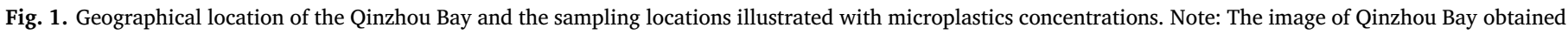

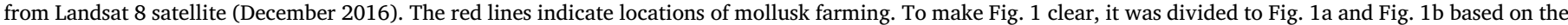

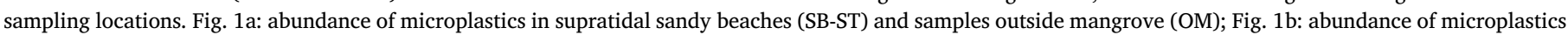

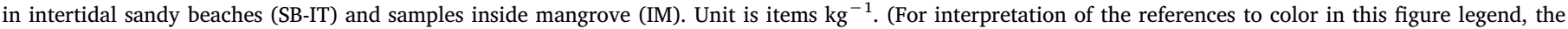
reader is referred to the web version of this article.)

counted and characterized according to their type, shape, size, and color. Based on field data, we discussed the dominant sources and retention of microplastics.

\section{Materials and methods}

\subsection{Sampling and processing}

A total of 17 sediment samples were collected in the Qinzhou Bay from December 18, 2016 to December 21, 2016. The sampling sites were illustrated in Fig. 1a and b, and the detail information of each sampling site was listed in Table S1. At low tide, sandy and muddy sediment samples were collected from the top $2 \mathrm{~cm}$. Samples were taken from five separate $0.3 \mathrm{~m} \times 0.3 \mathrm{~m}$ quadrats and then homogenized. The air-dried samples were sieved using a stainless-steel mesh with pore size of 35 mesh (i.e. $5 \mathrm{~mm}$ ) to remove the large particles (i.e. $>5 \mathrm{~mm}$ ).

\subsection{Microplastic extraction}

Microplastics were extracted from beach sand and mangrove sediment samples using a modified flotation device (Fig. S1) based on Nuelle et al. (2014). According to the published studies (Nor and Obbard, 2014; Stolte et al., 2015; Karlsson et al., 2017), calcium chloride solution with a density of $1.38 \mathrm{~g} \mathrm{~cm}^{-3}$ was selected and used as concentrated saline solution to float microplastics. Briefly, $500 \mathrm{~g}$ of beach sand sample or $100 \mathrm{~g}$ of mangrove sediment sample were transferred into a $2.5 \mathrm{~L}$ beaker and then mixed with $2 \mathrm{~L}$ of concentrated saline solution. Sodium metaphosphate was added to mangrove sediment samples to prevent aggregation. The mixture was stirred using a glass stick for $15 \mathrm{~min}$, meanwhile turn on the aeration pump to accelerate the separation of microplastics and sediments. A settling time was setted for $24 \mathrm{~h}$. Then, the solution was sieved using a stainless-steel mesh with pore size of 300 mesh (i.e. $50 \mu \mathrm{m}$ ) with the help of peristaltic pump (WT600-2 J, LONGER). The extraction of each sample was repeated twice. The plastic particles were identified using a magnifier with a magnification of $10 \times$. The properties used to identify plastics were based on published studies (Nor and Obbard, 2014; Peng et al., 2017). Identified microplastics were transferred to black cardboard and then photographed using a digital camera (EOS 60D, Canon). The photos were analyzed using software ParticleMFC which developed based on MATLAB 8.0 (Mathworks, Inc., Natick, MA) to count number of microplastics and measure the particle size and shape. Quality control and quality assurance was performed as described by Zhao et al. (2015) and Naji et al. (2017). Before extraction, the recovery experiment was conducted to evaluate the efficiency of this flotation device. Briefly, 150 particles belong to 5 types of plastic debris with particle size ranging from 0.5 to $5 \mathrm{~mm}$ were mixed with $500 \mathrm{~g}$ of clean sediment. The samples were extracted using the flotation equipment twice. Results show that the recoveries of five classes of microplastics ranged from $86.7 \%-100 \%$ (Table S2). 


\subsection{Characterization of microplastic}

To identify the type of microplastics, particles with the same shape and color were considered as the same type. Then the polymer composition of 28 items were identified using a FT-IR spectroscopy (Nicolet iS10, Thermo Fisher, USA) equipped with a platinum ATR single reflection diamond crystal-based module in the mid IR range $\left(525-4000 \mathrm{~cm}^{-1}\right)$. Before analyzing, 30\% hydrogen peroxide $\left(\mathrm{H}_{2} \mathrm{O}_{2}\right)$ was employed to remove biogenic material based on the method established by Tagg et al. (2015). Sixteen scans and $4 \mathrm{~cm}^{-1}$ resolution were applied in recording the spectra using DTGS detector. The obtained spectrums were compared with the standard database provided by the OMNIC software (Thermo Scientific Inc., USA). The microscopic morphological characteristics and element composition on the surface of microplastic were analyzed by a Scanning Electron Microscope-Energy Dispersive Spectrometer (SEM-EDS) (S-4800, Hitachi, Japan).

\section{Results and discussion}

\subsection{Abundance and distribution of microplastics}

Microplastics were detected in all 17 sediment samples, with concentrations ranging from 15 to 12,852 items $\mathrm{kg}^{-1}$ (Table 1). The concentration of microplastics in sandy beaches was $3266.0 \pm 6390.8$ items $\mathrm{kg}^{-1}$. The coefficient of variation (CV) of microplastic abundances in sandy beaches was $>1.0$ (Table 1), indicating that the abundance of microplastics in sandy beaches was highly variable. The abundance of microplastics in SB1-ST, SB2-IT, and SB3-ST (20-116 items $\mathrm{kg}^{-1}$ ) were in the same order of magnitude with those reported in the Bohai beach (94-201 items $\mathrm{kg}^{-1}$ ) of China (Yu et al., 2016) and coastal beach (56-130 items kg ${ }^{-1}$ ) of Belgium (Claessens et al., 2011). However, concentration of microplastics in SB2-ST $\left(12,852\right.$ items kg $\left.{ }^{-1}\right)$ was much higher than other beaches around the world (Vianello et al., 2013; Dekiff et al., 2014; Laglbauer et al., 2014; Esiukova, 2017). Compared with the location of SB1-ST and SB3-ST, there were lots of mollusk rafts near SB2-ST (Fig. 1). In addition, the beach of SB2-ST was covered with coastal vegetation. Intensive mollusk aquaculture was usually accompanied with lots of styrofoam waste. Styrofoam wastes transported by surface current to beaches, and vegetation could trap them. These reasons may make location of SB2-ST a hotspot for microplastics pollution.

The concentration of microplastics in sediments outside of mangroves ranged from 306 to 6168 items $\mathrm{kg}^{-1}$ and the average concentration was $2174.5 \pm 2206.8$ items $\mathrm{kg}^{-1}$. The abundance of microplastics in sediments outside of mangroves was also highly variable, as demonstrated by the $\mathrm{CV}$ value $>1.0$ (Table 1 ). Comparatively, the abundance of microplastics in sediments inside of mangroves was much lower, with the mean concentration of $42.9 \pm 26.8$ items kg${ }^{-1}$. Abundances of microplastics in sediments inside of mangrove of the Qinzhou Bay were close to those in mangrove sediments of Singapore (Nor and Obbard, 2014) and Iran (Naji et al., 2017). One-way ANOVA indicates that microplastic contamination outside of mangrove was much serious than inside of mangrove $(p<0.05)$.

\subsection{Characterization of microplastics}

Overall, diameter of detected microplastics ranged from 0.16 to $5.0 \mathrm{~mm}$. Size distribution of microplastics collected from different sampling locations was inconsistent (Fig. 2a). $>35 \%$ of the microplastics collected from sandy beaches fell into the size ranging from 1 to $2 \mathrm{~mm}$, while percentages of the other four size classes were all $<20 \%$. For the microplastics collected from sediments outside mangrove, $<$ $4 \%$ of microplastics fell into the smallest size class (i.e. $<1 \mathrm{~mm}$ ). The size of microplastics collected from sediments inside mangrove ranged from 0.36 to $4.8 \mathrm{~mm}$. Unlike the size distribution of microplastics in outside mangroves, more than half of the microplastics $(61.3 \%)$ in sediments inside of mangroves were $<1 \mathrm{~mm}$. A study conducted in Singapore's coastal mangrove sediments (intertidal zones) also showed that approximately $90 \%$ of the microplastics had a diameter $<1 \mathrm{~mm}$ (Nor and Obbard, 2014). > 90\% of the microplastics on beaches of Fernando de Noronha fell into the size range from 1 to $5 \mathrm{~mm}$ (Ivar do Sul et al., 2009), which was close to our results. Different sources, extent of degradation, environmental factors (e.g. temperature and solar radiation), polymer type, and different sampling methods and resultant detection limits may explain the varied size distribution of microplastics on different study area.

As shown in Fig. $2 \mathrm{~b},>98 \%$ of total microplastics were white; transparent made up $1.1 \%$ of the total. The other four (i.e. yellow, green, red, and blue) colors were $<1 \%$ of the total. For the microplastics in sandy beaches and sediments outside of mangrove, their color percentage distribution was similar to the total microplastics. However, color of microplastics in sediments inside of mangrove was mainly white and transparent. Previous studies have demonstrated that most microplastics collected from sediments or sandy beaches are white or transparent (Corcoran et al., 2015; Veerasingam et al., 2016; Young and Elliott, 2016), which was agreed with our study. However, Peng et al. (2017) reported that more than half of microplastics found in sediments of the Changjiang Estuary are multicolor, which suggested

Table 1

Summarize and statistics of microplastics abundance for different sample types.

\begin{tabular}{|c|c|c|c|c|c|c|}
\hline Sample type & Sample site & $\begin{array}{l}\text { Abundance } \\
\text { (items } \mathrm{kg}^{-1} \text { ) }\end{array}$ & $\begin{array}{l}\text { Average } \\
\left(\text { items } \mathrm{kg}^{-1} \text { ) }\right.\end{array}$ & $\begin{array}{l}\text { Median } \\
\left(\text { items } \mathrm{kg}^{-1} \text { ) }\right.\end{array}$ & SD & $\mathrm{CV}$ \\
\hline \multirow[t]{3}{*}{ Sandy beach } & SB1-ST & 76 & 3266.0 & 96.0 & 6390.8 & 1.96 \\
\hline & SB2-ST & 12,852 & & & & \\
\hline & SB2-IT & 20 & & & & \\
\hline \multirow{4}{*}{ Sediment outside mangrove } & OM1 & 1298 & 2174.5 & 1370.5 & 2206.8 & 1.01 \\
\hline & OM2 & 6168 & & & & \\
\hline & OM4 & 1443 & & & & \\
\hline & OM7 & 598 & & & & \\
\hline \multirow{6}{*}{ Sediment inside mangrove } & IM1 & 20 & 42.9 & 35.0 & 26.8 & 0.62 \\
\hline & IM2 & 70 & & & & \\
\hline & IM3 & 80 & & & & \\
\hline & IM4 & 20 & & & & \\
\hline & IM5 & 15 & & & & \\
\hline & IM6 & 60 & & & & \\
\hline
\end{tabular}

Note: SD: standard deviation, CV: coefficient of variation. 
a

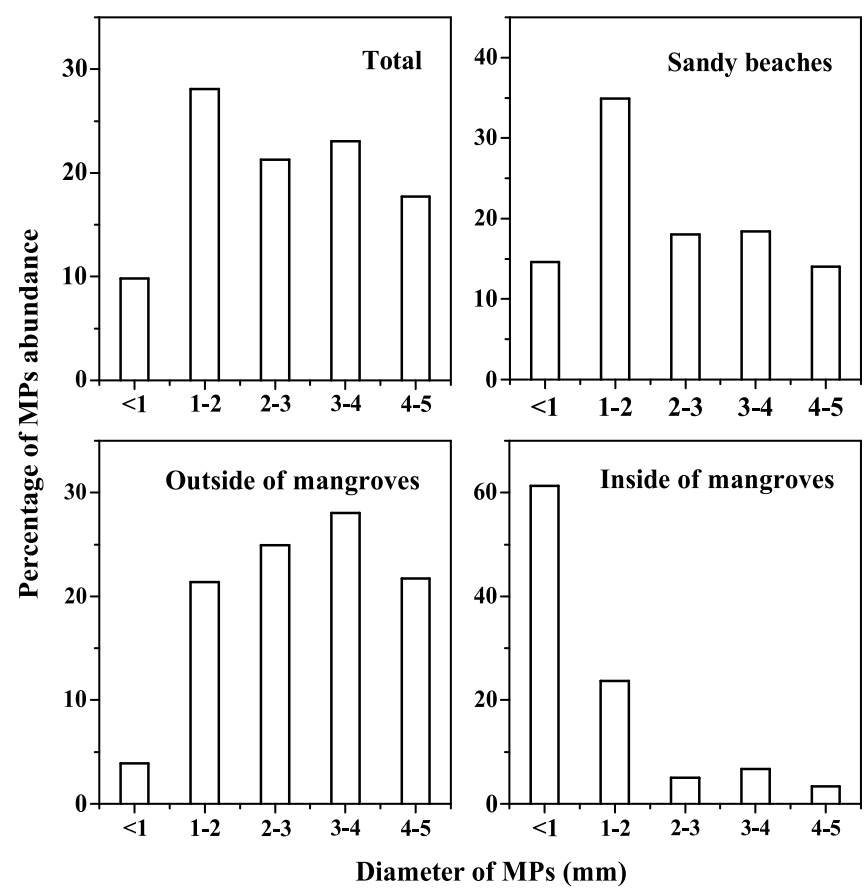

b

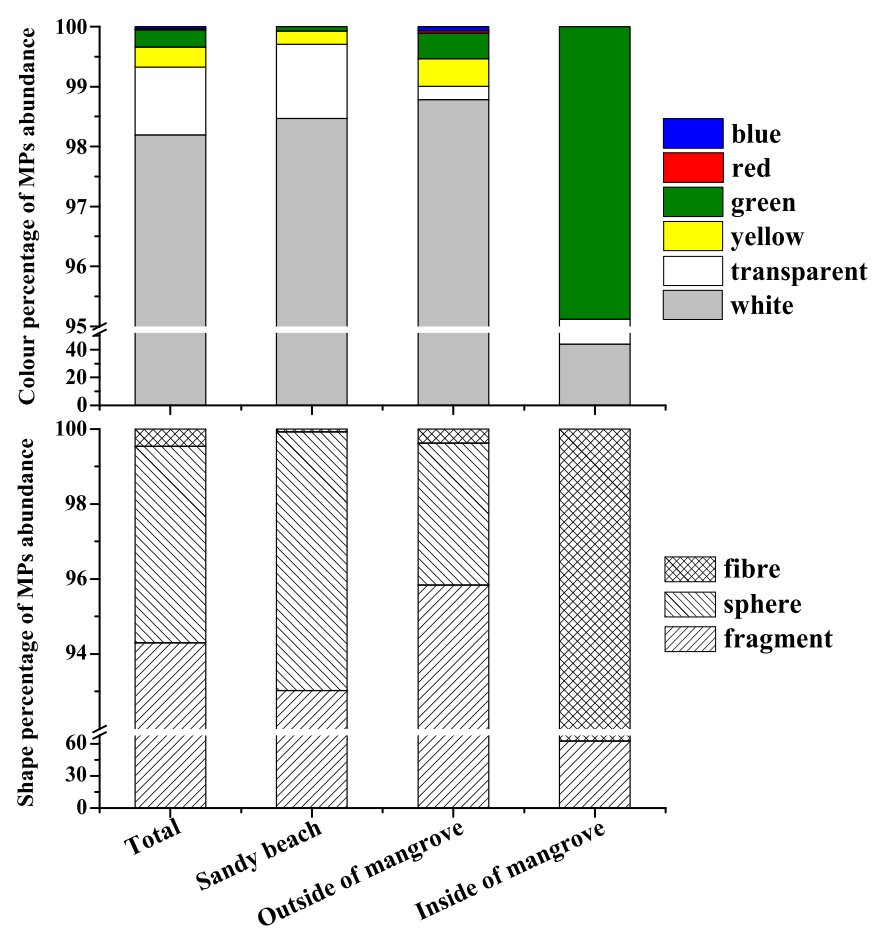

Fig. 2. Physical characterization of microplastics in different sample types. a: particle size distribution; b: color and shape distribution.

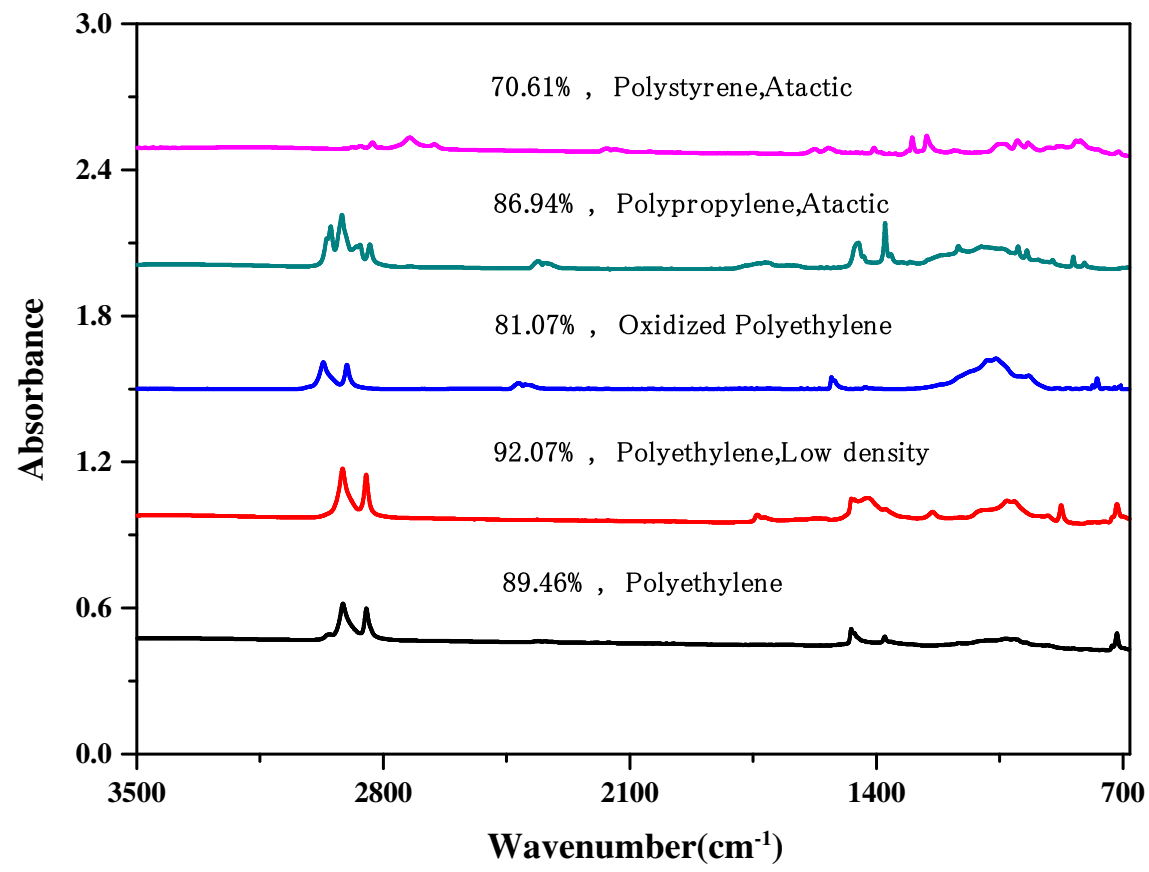

Fig. 3. The FTIR spectrum of selected microplastics and the match degrees with the standard spectrum.

that laundering clothes is the main source. This indicated that colors of microplastics were related to their sources.

Three shapes (i.e. fiber, sphere, and fragment) were identified, and pictures of microplastics with different shapes were shown in Fig. S2. Among the total microplastics, fragment was the most common shape, accounting to about $94 \%$; followed by sphere (5.2\%) and fiber $(0.5 \%)$ (Fig. 2b). The shape of great majority of microplastics in sandy beaches and sediments outside of mangrove were also fragment (>93\%). In contrast, fragment and fiber were the two only shapes can be found in sediments inside of mangrove, and the percentage of two shapes was close. Due to different pollutant sources and environmental processes (e.g. erosion, solar radiation, biodegradation), microplastics detected in coastal environment may be in regular and irregular shapes. The regular shapes typically come from a direct release (primary microplastics), which include pellet, bead, or spherule; while the irregular shapes mainly arise from degradation of larger plastic debris (secondary microplastics), which contain fiber, fragment, and other irregular shapes (Khatmullina and Isachenko, 2016). High temperatures and strong solar ultraviolet light associated with tropical climate can accelerate the degradation of large plastic debris in supratidal zones 
a

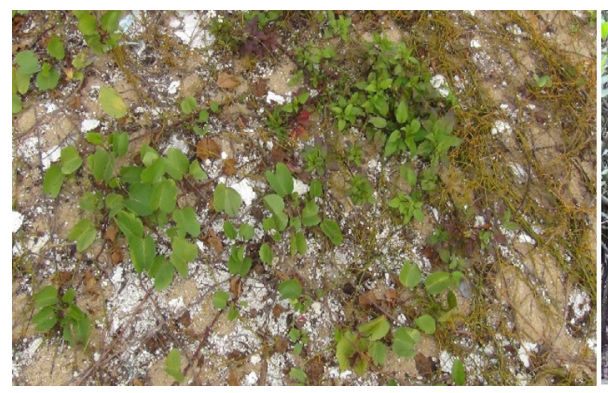

b

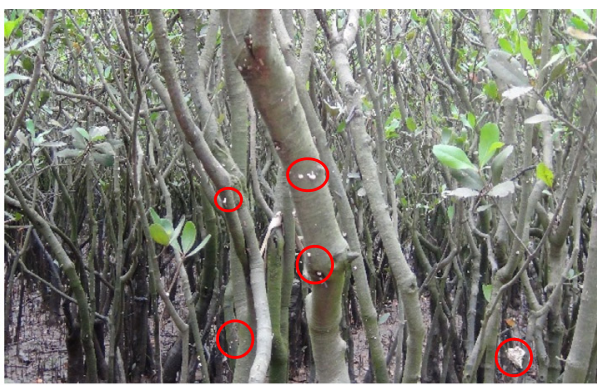

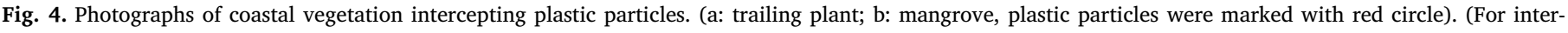
pretation of the references to color in this figure legend, the reader is referred to the web version of this article.)

(Lambert et al., 2013). Accordingly, our results show that $>93 \%$ of microplastics in the beaches and sediments outside mangrove were fragment. Different from the earlier studies (Acosta-Coley and OliveroVerbel, 2015; Fok et al., 2017), there was no virgin pellets observed in this study. The shape of microplastics indicated that microplastics in the Qinzhou Bay were mainly secondary microplastics formed by fragmentation of larger plastic debris.

During their cracking processes, the surface morphology of plastic particles may change significantly due to the erosion and biofouling (Imhof et al., 2013). The surface of microplastics may become rough and cracks may appear. Then, the clay minerals and quartz grains could embed in the pores or cracks of microplastics (Kowalski et al., 2016). SEM-EDS results in present study verified this conclusion (Fig. S3a, b). However, other microplastics showed a relatively smooth surface (Fig. S3c). Overall, different microplastic fragments showed the different morphology of surface. This could be relevant to the exposure time, physicochemical properties of plastic, and environmental factors.

As shown in Fig. 3, five plastic debris categories (i.e. PS, PP, PE, oxidized PE, and low-density PE) can be identified, with a mean match degree of $84.03 \%$. The match degrees of three PE categories were relatively high, followed with the PP category, while the match degree of PS was only 70.61\%. Fok et al. (2017) also reported that the match degrees of PS forms were lower than PP and PE. Weathering, ageing, and adherence might influence the match degrees of microplastics with standard database. Statistical results indicate that PS is the major polymer type of microplastics ( $>98 \%$ ).

\subsection{Source and retention of microplastics in the Qinzhou Bay}

Determining the sources of microplastics is a challenging task due to their complexity of sources and transform/transport processes. Physical and chemical characteristics of microplastics has been used to infer the source of microplastics (Browne et al., 2011; Peng et al., 2017). Further, the spatial distribution of microplastics can provide important clue on the release location of plastics (Heo et al., 2013; Lee et al., 2013; Yu et al., 2016). Our results indicate that PS is the major polymer type of microplastics ( $>98 \%$ ). This is not surprising since PS is extensively used to support the mollusk rafts in the Qinzhou Bay. As shown in Fig. 1, concentrations of microplastics in locations near the mollusk farming, that is ST2, M1, M2, M4, and M6, were much higher than those far from mollusk rafts. The large styrofoam wastes transported to beaches and coastal wetlands, where styrofoam wastes will fragment to microplastics under the high temperature and strong solar radiation (Andrady, 2011). Correspondingly, the majority of the detected microplastics in the Qinzhou Bay were fragment (Fig. 2b). In addition, the $\mathrm{PP}$ and PE were also widely used in aquaculture (e.g. woven bag, fish net). Thus, the major source of the microplastic in sediments of the Qinzhou Bay is mollusk aquaculture.

The dense vegetation of wetlands may effectively retain microplastics floating on the surface seawater (Sutton et al., 2016). As shown in Fig. 4, microplastic particles could adhere to trunks of mangroves and the trailing plant in beaches seem to trap microplastics. The intercept of coastal vegetation could prevent stranded microplastics from entering the sea. On the other hand, mangroves might restrict floating microplastics stranding on land. A survey of microplastics in wetlands might drastically revise our estimation of the standing stocks of plastics in the marine environment (Nor and Obbard, 2014). Therefore, more researches are warranted to investigate the important role of wetlands in determining the fate and transport of microplastics in coastal water.

\section{Conclusions}

Microplastics with sizes ranged from 0.16 to $5.0 \mathrm{~mm}$ were identified in sandy beaches and intertidal mangrove sediments of the Qinzhou Bay. Based on FTIR analysis, the majority of detected microplastics were white PS. The varicolored PP and PE were also found but their concentration were relatively low. Majority of the microplastics were in fragment shape, which indicated that microplastics in the Qinzhou Bay were mainly secondary microplastics. Microplastics abundance were high in locations close to mollusk farming. Sediments were embedded in cracks of microplastics. Coastal vegetation (e.g. mangrove and trailing plant) served as traps of plastic particles. Overall, microplastics pollution in sediments of Qinzhou Bay were mainly a result of intensive mollusk aquaculture. There is urgent need to regulate plastic wastes used for aquaculture and to replace traditional mollusk rafts by environmental-friendly materials.

\section{Acknowledgements}

This study was financially supported by National Key R \& D projects focus on special projects (2016YFC1402202) and the Key projects of foreign cooperation of Chinese Academy of Sciences (KYSB20160003).

\section{Appendix A. Supplementary data}

Supplementary data to this article can be found online at https:// doi.org/10.1016/j.marpolbul.2018.09.025.

\section{References}

Acosta-Coley, I., Olivero-Verbel, J., 2015. Microplastic resin pellets on an urban tropical beach in Colombia. Environ. Monit. Assess. 187, 1-14.

Andrady, A.L., 2011. Microplastics in the marine environment. Mar. Pollut. Bull. 62, 1596-1605.

Auta, H.S., Emenike, C.U., Fauziah, S.H., 2017. Distribution and importance of microplastics in the marine environment: a review of the sources, fate, effects, and potential solutions. Environ. Int. 102, 165-176.

Bakir, A., Rowland, S.J., Thompson, R.C., 2014. Enhanced desorption of persistent organic pollutants from microplastics under simulated physiological conditions. Environ. Pollut. 185, 16-23.

Batel, A., Linti, F., Scherer, M., Erdinger, L., Braunbeck, T., 2016. Transfer of benzo a pyrene from microplastics to Artemia nauplii and further to zebrafish via a trophic food web experiment: CYP1A induction and visual tracking of persistent organic 
pollutants. Environ. Toxicol. Chem. 35, 1656-1666.

Browne, M.A., Crump, P., Niven, S.J., Teuten, E., Tonkin, A., Galloway, T., Thompson, R., 2011. Accumulation of microplastic on shorelines woldwide: sources and sinks. Environ. Sci. Technol. 45, 9175-9179.

Claessens, M., De Meester, S., Van Landuyt, L., De Clerck, K., Janssen, C.R., 2011. Occurrence and distribution of microplastics in marine sediments along the Belgian coast. Mar. Pollut. Bull. 62, 2199-2204.

Corcoran, P.L., Norris, T., Ceccanese, T., Walzak, M.J., Helm, P.A., Marvin, C.H., 2015 Hidden plastics of Lake Ontario, Canada and their potential preservation in the sediment record. Environ. Pollut. 204, 17-25.

Dekiff, J.H., Remy, D., Klasmeier, J., Fries, E., 2014. Occurrence and spatial distribution of microplastics in sediments from Norderney. Environ. Pollut. 186, 248-256.

Esiukova, E., 2017. Plastic pollution on the Baltic beaches of Kaliningrad region, Russia. Mar. Pollut. Bull. 114, 1072-1080.

Fok, L., Cheung, P.K., Tang, G., Li, W.C., 2017. Size distribution of stranded small plastic debris on the coast of Guangdong, South China. Environ. Pollut 220, 407-412.

Guo, X., Wang, X., Zhou, X., Kong, X., Tao, S., Xing, B., 2012. Sorption of four hydrophobic organic compounds by three chemically distinct polymers: role of chemical and physical composition. Environ. Sci. Technol. 46, 7252-7259.

Heo, N.W., Hong, S.H., Han, G.M., Hong, S., Lee, J., Song, Y.K., Jang, M., Shim, W.J., 2013. Distribution of small plastic debris in cross-section and high strandline on Heungnam Beach, South Korea. Ocean Sci. J. 48, 225-233.

Hueffer, T., Hofmann, T., 2016. Sorption of non-polar organic compounds by micro-sized plastic particles in aqueous solution. Environ. Pollut. 214, 194-201.

Imhof, H.K., Ivleva, N.P., Schmid, J., Niessner, R., Laforsch, C., 2013. Contamination of beach sediments of a subalpine lake with microplastic particles. Curr. Biol. 23, R867-R868.

Ivar do Sul, J.A., Costa, M.F., 2014. The present and future of microplastic pollution in the marine environment. Environ. Pollut. 185, 352-364.

Ivar do Sul, J.A., Spengler, A., Costa, M.F., 2009. Here, there and everywhere. Small plastic fragments and pellets on beaches of Fernando de Noronha (equatorial Western Atlantic). Mar. Pollut. Bull. 58, 1236-1238.

Karlsson, T.M., Vethaak, A.D., Almroth, B.C., Ariese, F., van Velzen, M., Hassellov, M., Leslie, H.A., 2017. Screening for microplastics in sediment, water, marine invertebrates and fish: method development and microplastic accumulation. Mar. Pollut. Bull. 122, 403-408.

Khatmullina, L., Isachenko, I., 2016. Settling velocity of microplastic particles of regular shapes. Mar. Pollut. Bull. 114, 871-880.

Koelmans, A.A., Besseling, E., Foekema, E.M., 2014. Leaching of plastic additives to marine organisms. Environ. Pollut. 187, 49-54.

Kowalski, N., Reichardt, A.M., Waniek, J.J., 2016. Sinking rates of microplastics and potential implications of their alteration by physical, biological, and chemical factors. Mar. Pollut. Bull. 109, 310-319.

Laglbauer, B.J.L., Franco-Santos, R.M., Andreu-Cazenave, M., Brunelli, L., Papadatou, M., Palatinus, A., Grego, M., Deprez, T., 2014. Macrodebris and microplastics from beaches in Slovenia. Mar. Pollut. Bull. 89, 356-366.

Lambert, S., Sinclair, C.J., Bradley, E.L., Boxall, A.B., 2013. Effects of environmental conditions on latex degradation in aquatic systems. Sci. Total Environ. 447, 225-234.

Lee, J., Hong, S., Song, Y.K., Hong, S.H., Jang, Y.C., Jang, M., Heo, N.W., Han, G.M., Lee, M.J., Kang, D., Shim, W.J., 2013. Relationships among the abundances of plastic debris in different size classes on beaches in South Korea. Mar. Pollut. Bull. 77, 349-354.
Li, W.C., Tse, H.F., Fok, L., 2016. Plastic waste in the marine environment: a review of sources, occurrence and effects. Sci. Total Environ. 566, 333-349.

Li, J., Zhang, K.N., Zhang, H., 2018. Adsorption of antibiotics on microplastics. Environ. Pollut. 237, 460-467.

Mathalon, A., Hill, P., 2014. Microplastic fibers in the intertidal ecosystem surrounding Halifax Harbor, Nova Scotia. Mar. Pollut. Bull. 81, 69-79.

Moret-Ferguson, S., Law, K.L., Proskurowski, G., Murphy, E.K., Peacock, E.E., Reddy, C.M., 2010. The size, mass, and composition of plastic debris in the western North Atlantic Ocean. Mar. Pollut. Bull. 60, 1873-1878.

Naji, A., Esmaili, Z., Mason, S.A., Vethaak, A.D., 2017. The occurrence of microplastic contamination in littoral sediments of the Persian Gulf, Iran. Environ. Sci. Pollut. Res. 24, 20459-20468.

Nor, N.H.M., Obbard, J.P., 2014. Microplastics in Singapore's coastal mangrove ecosystems. Mar. Pollut. Bull. 79, 278-283.

Nuelle, M.T., Dekiff, J.H., Remy, D., Fries, E., 2014. A new analytical approach for monitoring microplastics in marine sediments. Environ. Pollut. 184, 161-169.

Peng, G.Y., Zhu, B.S., Yang, D.Q., Su, L., Shi, H.H., Li, D.J., 2017. Microplastics in sediments of the Changjiang Estuary, China. Environ. Pollut. 225, 283-290.

Stolte, A., Forster, S., Gerdts, G., Schubert, H., 2015. Microplastic concentrations in beach sediments along the German Baltic coast. Mar. Pollut. Bull. 99, 216-229.

Sutton, R., Mason, S.A., Stanek, S.K., Willis-Norton, E., Wren, I.F., Box, C., 2016. Microplastic contamination in the San Francisco Bay, California, USA. Mar. Pollut. Bull. 109, 230-235.

Tagg, A.S., Sapp, M., Harrison, J.P., Ojeda, J.J., 2015. Identification and quantification of microplastics in wastewater using focal plane array-based reflectance micro-FT-IR imaging. Anal. Chem. 87, 6032-6040.

Van Cauwenberghe, L., Janssen, C.R., 2014. Microplastics in bivalves cultured for human consumption. Environ. Pollut. 193, 65-70.

Veerasingam, S., Mugilarasan, M., Venkatachalapathy, R., Vethamony, P., 2016. Influence of 2015 flood on the distribution and occurrence of microplastic pellets along the Chennai coast, India. Mar. Pollut. Bull. 109, 196-204.

Vianello, A., Boldrin, A., Guerriero, P., Moschino, V., Rella, R., Sturaro, A., Da Ros, L., 2013. Microplastic particles in sediments of lagoon of Venice, Italy: first observations on occurrence, spatial patterns and identification. Estuar. Coast. Shelf Sci. 130, 54-61.

Weinstein, J.E., Crocker, B.K., Gray, A.D., 2016. From macroplastic to microplastic: degradation of high-density polyethylene, polypropylene, and polystyrene in a salt marsh habitat. Environ. Toxicol. Chem. 35, 1632-1640.

Woodall, L.C., Sanchez-Vidal, A., Canals, M., Paterson, G.L.J., Coppock, R., Sleight, V., Calafat, A., Rogers, A.D., Narayanaswamy, B.E., Thompson, R.C., 2014. The deep sea is a major sink for microplastic debris. R. Soc. Open Sci. 1, 1-8.

Wright, S.L., Thompson, R.C., Galloway, T.S., 2013. The physical impacts of microplastics on marine organisms: a review. Environ. Pollut. 178, 483-492.

Young, A.M., Elliott, J.A., 2016. Characterization of microplastic and mesoplastic debris in sediments from Kamilo Beach and Kahuku Beach, Hawai'i. Mar. Pollut. Bull. 113, $477-482$.

Yu, X.B., Peng, J.P., Wang, J.D., Wang, K., Bao, S.W., 2016. Occurrence of microplastics in the beach sand of the Chinese inner sea: the Bohai Sea. Environ. Pollut. 214 722-730.

Zhao, S.Y., Zhu, L.X., Li, D.J., 2015. Microplastic in three urban estuaries, China. Environ. Pollut. 206, 597-604. 